\title{
Grid dispersion and filtering in broadband acoustic emission (AE) source modeling
}

\author{
Siddhesh Raorane ${ }^{1}$ (D), Paweł Paćko ${ }^{2}$ (D) \\ 1 AGH University of Science and Technology, Academic Centre for Materials and Nano- \\ technology, Krakow \\ 2 AGH University of Science and Technology, Faculty of Mechanical Engineering and Robotics, \\ Department of Robotics and Mechatronics, Krakow
}

\begin{abstract}
The spatial grid of numerical models of acoustic emission (AE) sources acts as a spatial filter for elastic wave signals. The filtering effects are particularly prominent for short-time, broadband signals - typical for AE. In this paper, we investigate the filtering influence of spatial discretization (meshing) on broadband AE source modeling. The AE source - generating AEs propagating as elastic waves - was modeled using cohesive zone approach, and the numerical simulations were performed in commercial FEM software COMSOL Multiphysics. Results were processed using Fast Fourier Transform, filtered, and subsequently analyzed in terms of the filtering effects of spatial discretization on AE source modeling. In this paper, it is shown that spatial grids in numerical models effectively work like low-pass filters with the cut-off frequency corresponding to the numerical Brillouin zone. The latter induces short wavelength limitation, and the frequency components near (below) the zone edge are amplified in magnitude. It was found that the amplified frequencies represent numerical errors. Also, it was inferred that the filtering effect of spatial discretization can mask the AE source characteristics and affect the quality of the results.
\end{abstract}

Keywords: acoustic emission source, finite element modeling, cohesive zone approach, grid dispersion, signal processing, elastic waves

\section{DYSPERSJA SIATKI I FILTRACJA SYGNAŁÓW W MODELOWANIU SZEROKOPASMOWYCH ŹRÓDEŁ EMISJI AKUSTYCZNEJ}

Streszczenie: Siatki przestrzenne modeli numerycznych mają własności filtrów, ujawniające się w szczególności w krótkotrwałych, szerokopasmowych zjawiskach dynamicznych typowych dla emisji akustycznej (AE). W artykule poddano analizie wpływ filtrowania, spowodowanego siatką przestrzenną, na modelowe sygnały AE. Źródło emisji akustycznej zamodelowane zostało z wykorzystaniem stref kohezji, a symulacje wykonano w oprogramowaniu COMSOL Multiphysics. Wyniki uzyskane z dynamicznej analizy przejściowej poddano analizie, wykorzystując szybką transformatę Fouriera oraz filtrację w dziedzinie częstotliwości, a następnie zbadano wpływ siatki przestrzennej na zawartość częstotliwościową uzyskanych sygnałów. W artykule pokazano, że siatki mają charakter dolnoprzepustowych filtrów przestrzennych o częstotliwości odcięcia równej brzegowi numerycznej strefy Brillouina dla badanego modelu. Strefa ta uniemożliwia propagację fal krótkich, których częstotliwość jest wyższa od jej granicy, lecz również wzmacnia amplitudy fal o częstotliwościach niższych. Te ostatnie, zdeformowane komponenty częstotliwościowe, mają charakter błędów numerycznych i zmieniają obraz fizycznych cech źródła emisji akustycznej oraz pogarszają jakość uzyskiwanych wyników symulacji.

Słowa kluczowe: źródła emisji akustycznej, metoda elementów skończonych, strefy kohezji, dyspersja siatki, przetwarzanie sygnałów, fale sprężyste

https://doi.org/10.7494/978-83-66727-48-9_10 


\section{Introduction}

Elastic waves find applications across various fields of engineering and science (Cheeke 2017). They are frequently used in mining and geological engineering owing to two unique phenomena, namely, reflection and distortion of the signal when encountering a change in material property (e.g. a void), and emission of elastic waves when distributed or localized micro-displacements occur in a material.

Oil and gas explorations have been employing guided elastic waves to determine the presence of reservoirs (see e.g. "Reflection Seismology") wherein elastic waves are induced in the Earth with the help of transducers, and the modified and/or reflected waves are picked up by special sensors. Elastic waves also accompany exploration processes and are, for instance, emitted as acoustic emission (AE) signals during the drilling process thus paving the path for the application of $\mathrm{AE}$ techniques (Grosse and Ohtsu 2008) in drilling/mining industry. The AE based techniques find far more applications than the guided waves' based methods in the drilling and mining industries, and are popularly used for prediction, estimation, monitoring and diagnosis (Khoshouei and Bagherpour 2019). A drill bit-rock interface monitoring technology capable of providing the operator with live information about the condition of the down-hole drill bit with acoustic emissions was outlined in Karakus and Perez (2014). A robust method for drilling monitoring using AE was proposed in Le Moal et al. (2012). Experiments showing the robustness and usefulness of the proposed method in drilling monitoring have been reported. More recently, in Bejger and Piasecki (2020), AEs were used for diagnosing high pressure mud pumps used on drilling rigs. The method reported in Bejger and Piasecki (2020) was verified by experiments conducted on a NOV (National Oilwell Varco)-made triplex 14-P-220 mud pump (mounted in the drillship).

AE-based techniques require extraction of the characteristics of the recorded AE signals making signal processing one of their important aspects. In Rao and Subramanyam (2008) the AE signals were analyzed using the wavelet transform. A combined method of Winger-Ville distribution signal processing method with a theoretical velocity dispersion model for AE source location in dispersive media was reported by Kim et al. (2013). In Yu et al. (2006), a study on the failure detection of composite materials using $\mathrm{AE}$ was reported wherein the $\mathrm{AE}$ signals were analyzed using Fast Fourier Transform (FFT). This short list is, of course, not exhaustive for signal processing methods for AE signals.

Although the application of AE is very popular in the drilling and mining industries, the dispersive nature of AE signals makes the correlation between the AE source and waveform features still unclear. Thus, AE based methods often require thorough and robust designing, prototyping, and testing, which are iterative and expensive. $\mathrm{Nu}-$ 
merical modeling of $\mathrm{AE}$ diminishes the dependence on expensive and time-consuming physical experiments making it an attractive and popular tool for predicting complex wavefields and help in the development of robust and reliable AE techniques. Modeling of buried monopole and dipole AE sources with a FEM technique was reported in Hamstad et al. (1999). An AE source model based on FEM approach was reported by Sause and Richler (2015). The authors in modeled the AE source as a crack based on cohesive zone element approach (Sause and Richler 2015).

Most of numerical models of AE sources require a spatial numerical grid (mesh). The spatial grid acts as a spatial filter for elastic wave signals. The filtering effects are particularly prominent for short-time, broadband signals that are typical for AE. In this paper, we investigate the filtering influence of spatial discretization (meshing) on AE source modeling using three different mesh configurations. Commercial FEM software COMSOL Multiphysics was employed to perform numerical simulations. The AE source - generating AEs propagating as elastic waves - was modeled using cohesive zone approach.

The paper is organized as follows. First, the modeling approach adopted in this paper is described. Next, results for three mesh configurations are presented, followed by their processing using Fast Fourier Transform (FFT), and filtering. Subsequently, the original and processed results are analyzed and discussed in terms of the filtering effects of the spatial discretization on AE source modeling. Lastly, conclusions are drawn from the analyzes.

\section{Model description}

The COMSOL Multiphysics commercial FEM software was employed to perform numerical simulations. All calculations presented herein were performed using the Structural Mechanics (SM) module of COMSOL. The Low-Reflecting Boundary (LRB) feature of the SM module was employed to absorb far-field outgoing waves. The LRB acts as an absorbing boundary layer, similar to a perfectly matched layer, preventing edge/boundary-reflected waves from interfering with source emissions within the analysis domain.

All simulations were performed under 2-D plane-strain conditions. The specimen geometry consisted of a notched square aluminum block with edge length of $0.5 \mathrm{~m}$. The acoustic emission source was modeled using the cohesive zone approach. In order to activate crack propagation, a point load was applied at the tip of the cohesive zone. The geometrical setup consisting of the cohesive zone and the point load can be seen in Figure 1a. The advancing crack propagation induces acoustic emissions propagating as elastic waves, as shown in Figure 1 b. 
a)

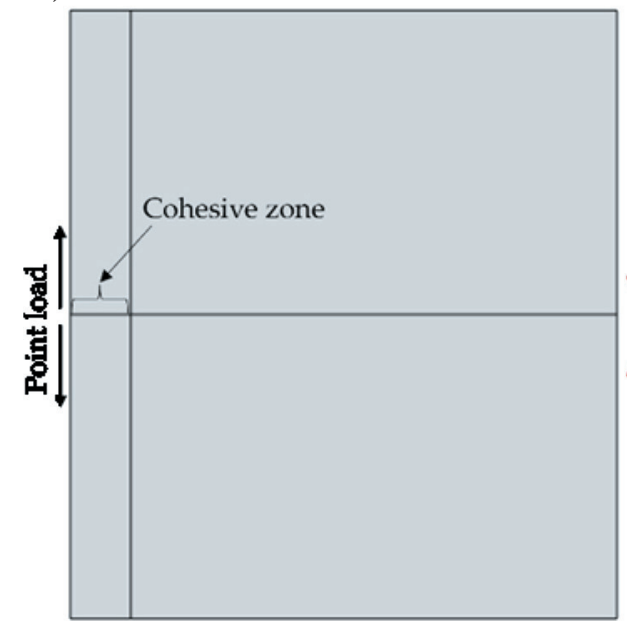

b)

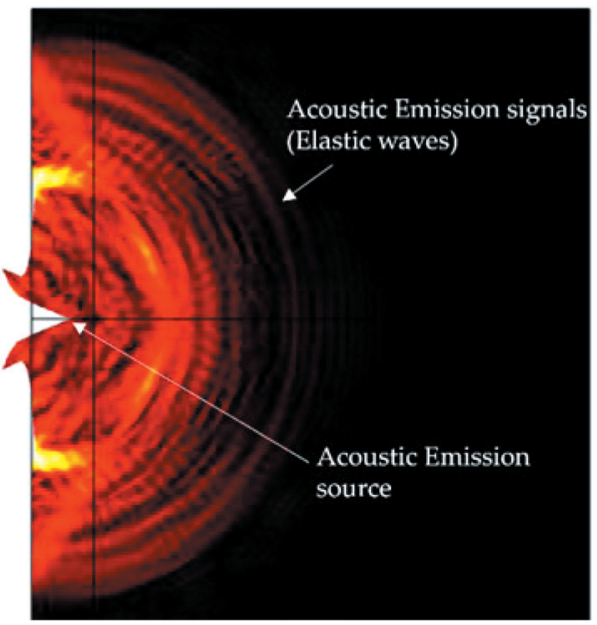

Fig. 1. The geometrical setup - used in the FEM simulations - consisting of the cohesive zone and the point load (a). Advancing crack propagation inducing acoustic emissions propagating as elastic waves for $M_{0}$ mesh configuration (coarse mesh) at a selected time instant (b). Please note that model distortion was rescaled for illustration purposes

Spatial numerical grid (mesh) of the model acts as a spatial filter for elastic waves signals. These filtering effects are particularly prominent for short-time, broadband signals typical for acoustic emission. To investigate the influence of spatial discretization (meshing) on the generated AE signals, the same model geometry was discretized with three different mesh configurations. The resultant element sizes varied from $0.01 \mathrm{~m}$ in $M_{0}$ mesh (coarse mesh), $0.005 \mathrm{~m}$ in $M_{1}$ mesh (fine mesh), to $0.002 \mathrm{~m}$ in $M_{2}$ mesh (finest mesh), as shown in Figure 2. Please note that the subscripts 0,1 and 2 are chosen only to represent the resolution of each mesh configuration, with 0 representing the lowest and 2 representing the highest resolutions. All the three mesh configurations can be seen in Figure 2; the coarse, fine and finest meshes being illustrated in Figures $2 \mathrm{a}, 2 \mathrm{~b}$ and $2 \mathrm{c}$, respectively. Please note that in each mesh configuration, the element size was kept constant throughout the model to avoid spurious/artificial reflections typical for meshes with varying spatial discretization (Raorane et al. 2021).

The time integration was carried out with the COMSOL built-in generalized-alpha time stepping scheme with a maximum step constraint of $0.01 \mu$ s used for all the numerical simulations. The maximum step constraint value was chosen small enough in order to remain well below the Nyquist limit of the propagating AE signals, i.e. in order to represent all relevant temporal frequency components of the generated signal - allowing for attributing signal distortions to the spatial grid dispersion only. 
The total simulation time was $80 \mu$ s for all configurations, and AE signals were recorded at a sensor point located at the same geometrical position for all three mesh configurations as shown in Figure 2. Please note that the horizontal and vertical velocities, instead of displacements, were recorded at the sensor point to avoid the DC (static displacement) component.

a)

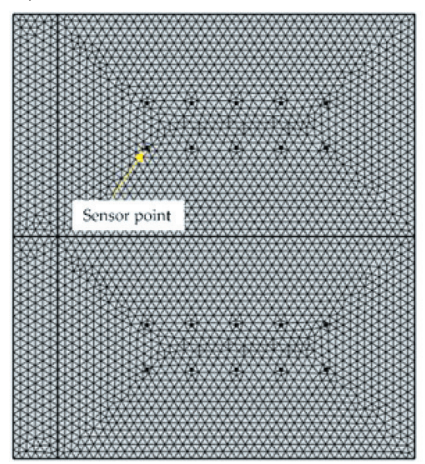

b)

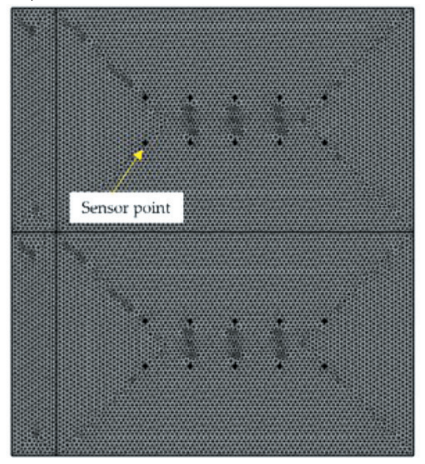

c)

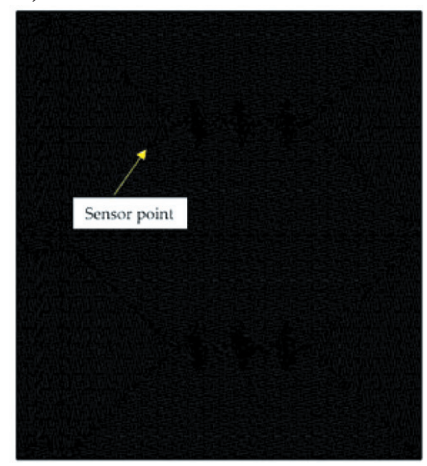

Fig. 2. Illustration of the different mesh configurations used in this paper: a) $M_{0}$ mesh configuration with element size $0.01 \mathrm{~m}$ (coarse mesh); b) $M_{1}$ mesh configuration with element size $0.005 \mathrm{~m}$ (fine mesh); c) $M_{2}$ mesh configuration with element size $0.002 \mathrm{~m}$ (finest mesh)

The simulation starts with a gradually-increasing point-load at each notch face, inducing decohesion and leading to the generation of acoustic emissions. The latter elastic waves are recorded at the sensor point. Example AEs from the source for $M_{0}$ configuration at a selected time instant can be seen in Figure $1 \mathrm{~b}$ (please note that model distortion was rescaled for illustration purposes).

\section{Results}

The elastic waves, emitted as AE signals, generated by the cohesive zone were recorded at the sensor point for all the three mesh configurations at all the time steps and compared. Figure 3 shows all the recorded AE signals. The velocities of the AE signals were recorded to avoid the DC shift in displacements. It can be clearly observed from Figure 3 that as the mesh resolution becomes finer, i.e., as the element size of the mesh decreases, the time domain signals smooths. Thus, the resulting signals are the most coarse for $M_{0}$ - represented by Figure $3 \mathrm{a}$ and the smoothest for $M_{2}$ - represented by Figure 3c. It should be emphasized that the time integration procedure type and parameters were the same, hence signal distortions are only due to spatial discretization. It can be observed for improving mesh accuracy (decreasing element size) that 
the acquired signals display more high frequency components, as expected. Interestingly, however, less moderate-frequency waves are present for finer meshes (see the substantial amplitude variations in Figures $3 a$ and $3 b$ ). The latter is in contrast with the anticipated signal shape convergence, where higher frequency components would be added on top of the signal when shorter waves are allowed by smaller elements.

a)

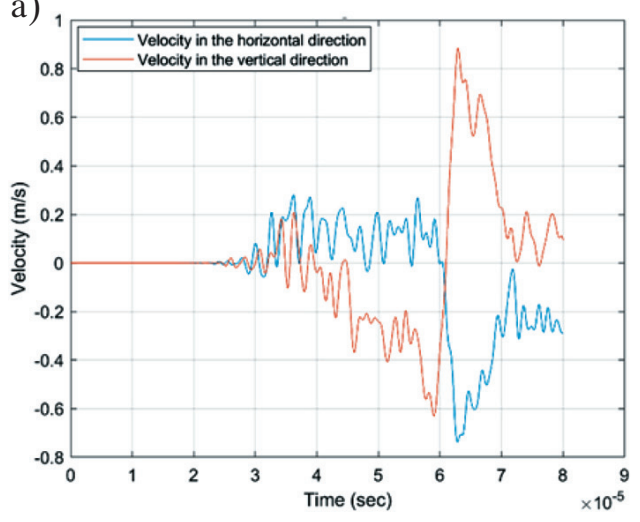

b)

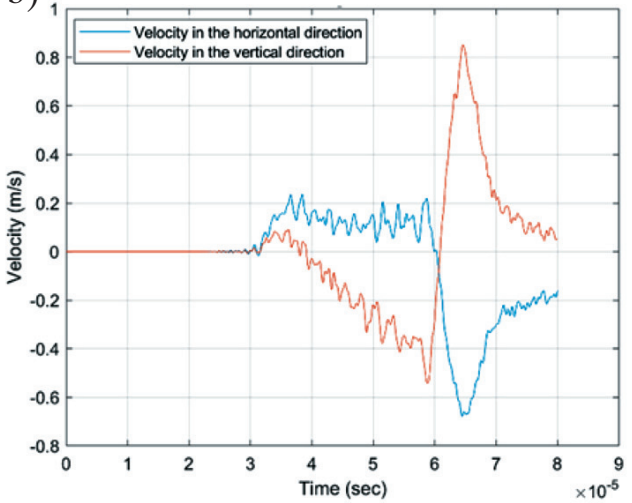

c)

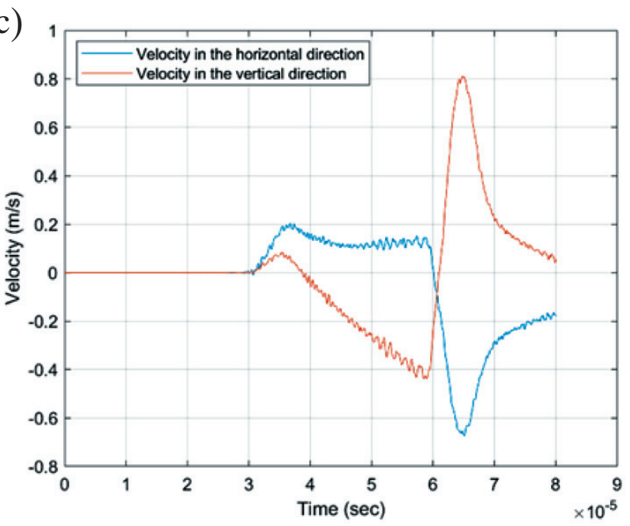

Fig. 3. The AE signals - generated by the cohesive zone - recorded at the sensor point for all the three mesh configurations at all the time steps: a) AE signals recorded for $M_{0}$ mesh configuration (coarse mesh) at all the time steps; b) AE signals recorded for $M_{1}$ mesh configuration (fine mesh) at all the time steps; c) AE signals recorded for $M_{2}$ mesh configuration

(finest mesh) at all the time steps. It can be observed that as the mesh resolution becomes finer, i.e., as the element size of the mesh decreases, the time domain signals smooths

\subsection{Fast Fourier Transform (FFT)}

In order to investigate the results in the frequency domain, Fast Fourier Transform (FFT) of the results presented in Figure 3 was performed. It must be noted that the FFT of the horizontal and vertical velocities give very similar results for the sensor 
point location chosen here, and thus the FFT of either one of the velocities can be performed in order to investigate the influence of the grid. In this paper, only the horizontal velocities were analyzed, as seen in Figure 4. It can be clearly observed from Figure 4 that as the mesh resolution becomes finer, the grid cut-off frequency increases such that for $M_{0}$ (coarse mesh) the cut-off frequency is approximately $0.9 \mathrm{kHz}$, for $M_{1}$ (fine mesh) the grid cut-off frequency is approximately $1.8 \mathrm{kHz}$, and for $M_{2}$ (finest mesh) the grid cut-off frequency is approximately $4.4 \mathrm{kHz}$, which is very near the time-step constrained Nyquist limit of $4.5 \mathrm{kHz}$. It can also be observed from Figure 4 that at very low frequencies $(<0.2 \mathrm{kHz})$, the FFT results for all the three configurations are the same.

a)

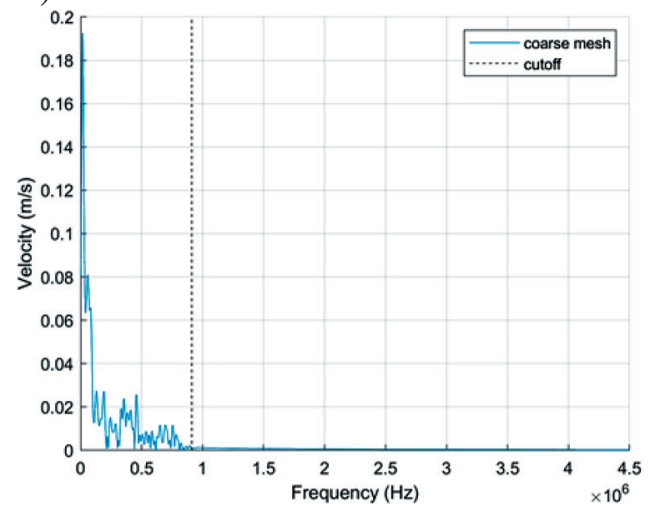

b)

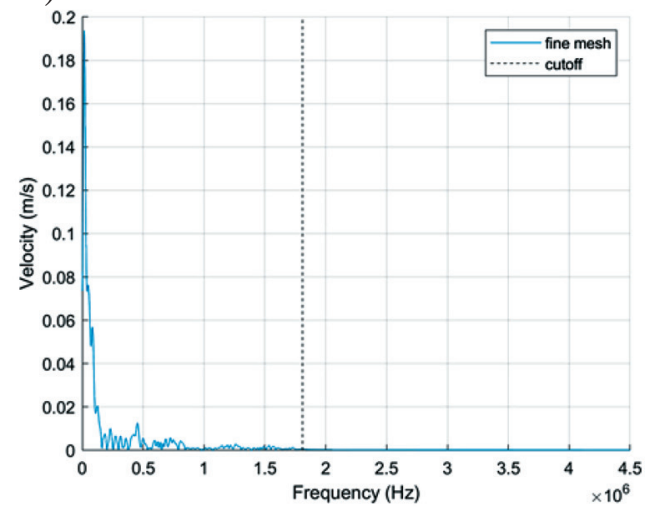

c)

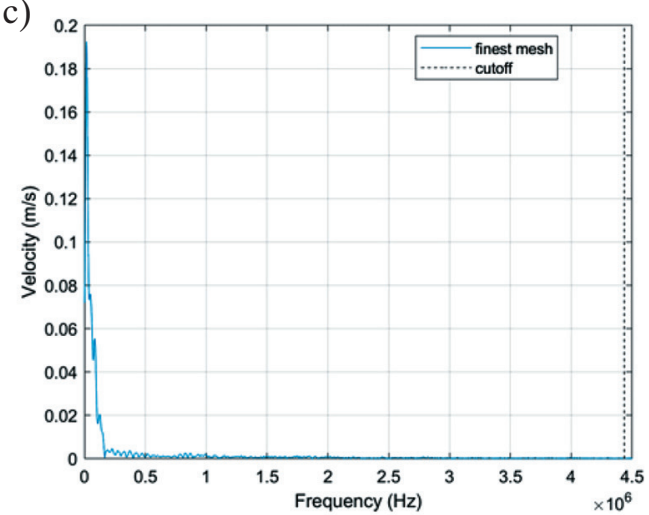

Fig. 4. Fast Fourier Transform (FFT) of the horizontal velocities of all the three mesh configurations presented in Figure 3: a) FFT of the horizontal velocities of $M_{0}$ mesh configuration (coarse mesh) presented in Figure 3a; b) FFT of the horizontal velocities of $M_{1}$ mesh configuration (fine mesh) presented in Figure 3b; c) FFT of the horizontal velocities of $M_{2}$ mesh configuration (finest mesh) presented in Figure 3c. It can be clearly observed that as the mesh resolution becomes finer, the grid cut-off frequency increases 


\subsection{Filtering}

To standardize our study with respect to frequency, the FFT results obtained in Figure 4 were passed through a low-pass filter, which was based on the cut-off frequency of the coarse mesh model $M_{0}$ represented by Figure 4a. Figure 5 shows the filtered FFT of all the mesh configurations, and it can be clearly seen that the cut-off frequency of all the configurations is now the same. The magnitude of the frequencies, however, is different for different configurations. The different magnitudes of frequencies can be clearly observed in Figure 5b, which represents a close-up view of Figure 5a.

a)

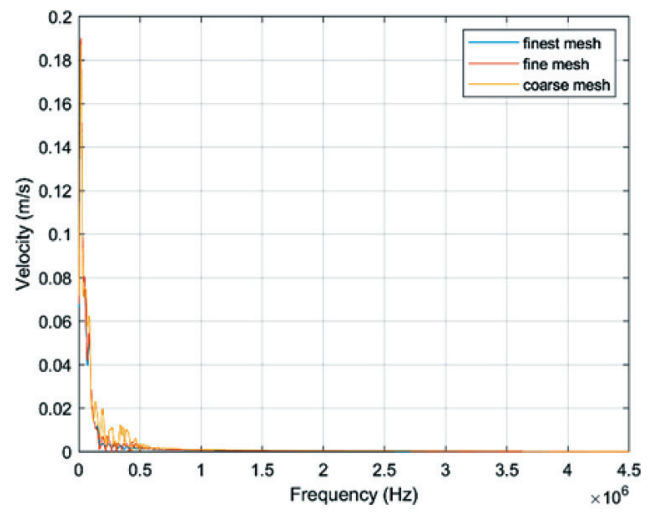

b)

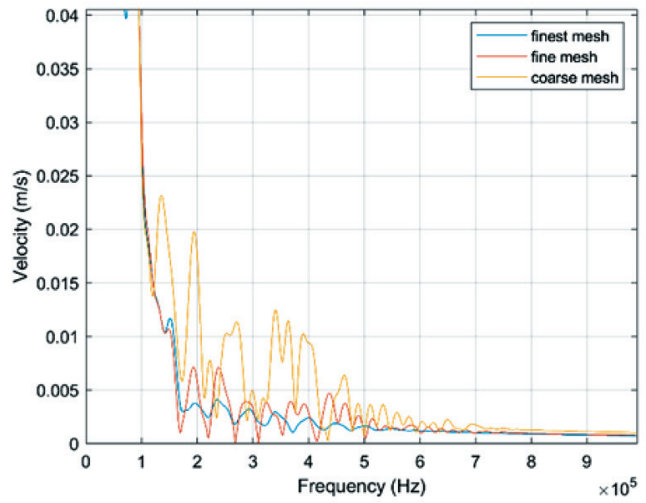

Fig. 5. Filtered FFT of all the three mesh configurations (a). A close-up view of Figure5a (b). It can be seen that even though the cut-off frequency of all the three configurations is now the same, the magnitude of the frequencies is different for different configurations

Applying the same low-pass frequency filter, previously used to obtain results presented in Figure 5, to the time domain results shown in Figure 3, filtered time domain signals were obtained for all the mesh configurations as seen in Figure 6. It can be observed from Figure 6 that the filtered time domain signals are smoother in comparison to their respective unfiltered counterparts (Fig. 3). It can also be observed from Figure 6 that although all the filtered time domain signals have the same frequencies proven by the filtered FFTs in Figure 5, the difference in smoothness among them, as observed in Figure 3, still persists such that the filtered signals from $M_{2}$ are the smoothest. Again, despite the signals containing the same band of frequencies, some components present in $M_{0}$ and $M_{1}$ are not seen in $M_{3}$. The latter observation is in contrast to the expected model convergence behavior. 
a)

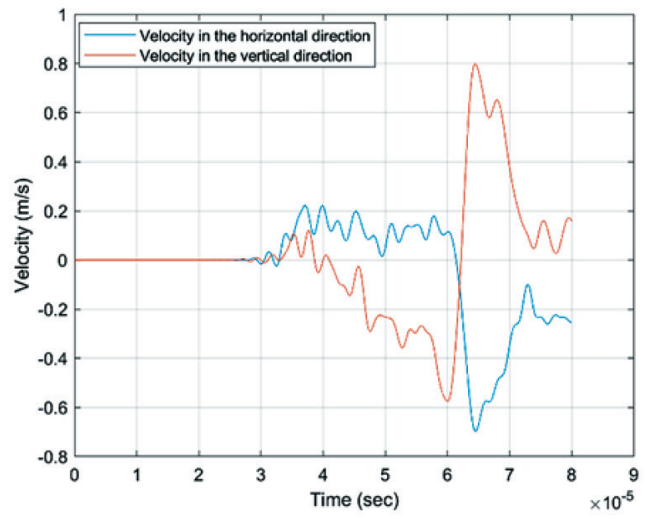

b)

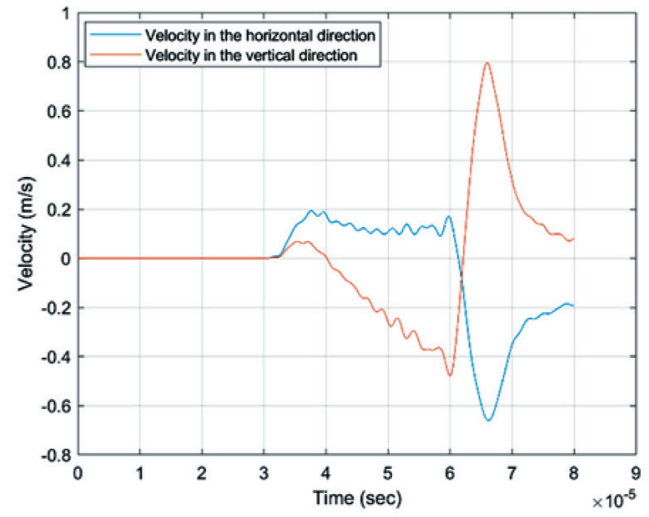

c)

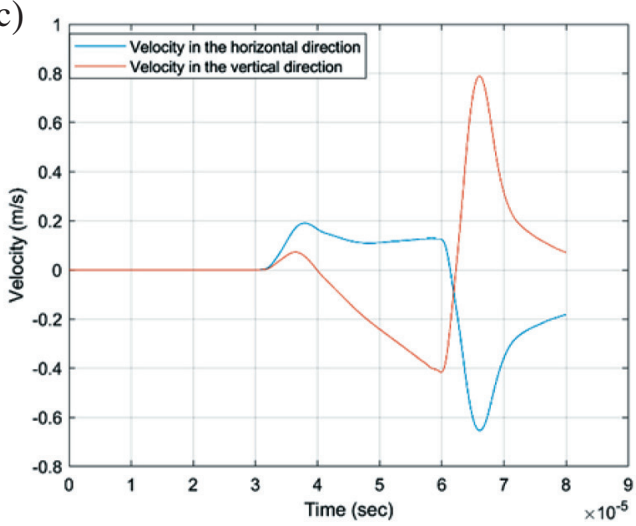

Fig. 6. Filtered time domain signals of all the three mesh configurations: a) filtered time domain signals of $M_{0}$ mesh configuration (coarse mesh); b) filtered time domain signals of $M_{1}$ mesh configuration (fine mesh); c) filtered time domain signals of $M_{2}$ mesh configuration

(finest mesh). It can be observed that although all the filtered time domain signals have the same frequencies - proven by the filtered FFTs in Figure 5, the difference in smoothness among them, as observed in Figure 3, still persists

\section{Discussion}

As noted in Section 3, and clearly observed in Figure 4, the cut-off frequency increases as the mesh resolution becomes finer. This increase in the cut-off frequency happens because the numerical Brillouin zone increases with finer mesh resolution. Here, the numerical Brillouin zone is related to the structure of the model - and not the material - such that the numerical Brillouin zone limitation is the short wavelength limitation that causes higher frequencies to be supported only by finer mesh resolutions. Thus, the numerical model acts like a filter, whose limit is determined by its 
mesh resolution, that lets frequencies below the numerical Brillouin zone limit pass through the model, and blocks all the frequencies that are higher than the numerical Brillouin zone limit. One of the key findings of the presented study indicates that the filtering property of the model, which is a function of its mesh resolution, deforms the passed frequencies such that some of them are amplified. The selective amplification property can be clearly observed in the filtered FFT results shown in Figure 5, wherein the limiting frequency is the same for all three configurations but the magnitudes of frequencies are different. The filtering characteristics of the numerical model cause the frequencies near the respective numerical Brillouin zones to be amplified because of amplitude-singularity. Therefore, magnitudes of the frequencies near the filter limit, which is the cut-off frequency of $M_{0}$, in Figure 5 are significantly higher for $M_{0}$ than the other two configurations. The amplified magnitudes of frequencies near the filtering limit observed in Figure 5 cause the filtered time domain signal for $M_{0}$ to be coarsest while the smoothest filtered time domain signals of $M_{2}$ represent presence of no amplified frequencies (as they have been filtered out by the low-pass filter).

The amplified frequencies represent numerical errors. They can mask the AE source characteristics, and it becomes vital to avoid or filter-out these in order to reduce erroneous results. Thus, choosing the mesh resolution is important for AE source models; and although a coarse mesh is computationally cheaper, the results are relatively erroneous. A multi-scale approach becomes an attractive option in this predicament such that a balance can be achieved between computational efficiency and the quality of results.

\section{Conclusions}

In this work, we investigated the filtering impact of spatial discretization on broadband AE source modeling. The investigation was based on the analysis of three different mesh configurations using a commercial FEM solver.

Results for the three mesh configurations were presented. The data were processed using Fast Fourier Transform (FFT) and filtered to be subsequently analyzed in terms of the filtering effects of spatial discretization on AE source modeling. It was found that grids effectively work as low-pass filters with the cut-off frequencies being a function of their spatial discretizations. The effective cut-off frequency - corresponding to the numerical Brillouin zone - induces the short wavelength limitation, hence frequencies near the numerical Brillouin zone are amplified in magnitude, followed by their blocking beyond that frequency. The amplified frequency waves 
represent numerical errors and can mask the AE source characteristics, affecting quality of the results.

The study reported here shows the significance of the choice of mesh resolution (size) for broadband wave phenomena. The latter are characteristic to seismic waves, acoustic emissions in soils, metals and composites during drilling, milling, mining and other processes. The mesh resolution, in seismic wave models, should be adjusted according to not just the topography but also the expected frequency range of the waves and include the possible amplification and distortion of waves near the numerical Brillouin zone limits. In particular, the cut-off property of the numerical Brillouin zone limit - leading to filtering out wave components beyond that frequency - causes also distortions of propagating wave components below the limiting frequency. Therefore, additional margin should be considered when designing the model in order to avoid erroneous interpretations of the acquired signals. Specifically, a coarse mesh choice - although computationally cheaper - may neglect certain geometrical features of the terrain and also affect/amplify the frequencies of interest, leading to interpretation errors resulting in poor predictions. A multi-scale approach thus becomes an attractive option for seismic wave simulation wherein a balance can be achieved between computational efficiency and the quality of results.

This project has received funding from the European Union's Horizon 2020 research and innovation programme under the Marie Skłodowska-Curie grant agreement no. 764547. The second author acknowledges support from the National Science Centre through the OPUS project no. 2018/31/B/ST8/00753.

\section{References}

Bejger A., Piasecki T., 2020, The Use of Acoustic Emission Elastic Waves for Diagnosing High Pressure Mud Pumps Used on Drilling Rigs, Energies, vol. 13(5), 1138. https:// doi.org/10.3390/en13051138.

Cheeke J.D.N., 2017, Fundamentals and Applications of Ultrasonic Waves, CRC Press.

Grosse C., Ohtsu M., 2008, Acoustic Emission Testing, Springer Science \& Business Media.

Hamstad M., O’Gallagher A., Gary J., 1999, Modeling of buried monopole and dipole sources of acoustic emission with a finite element technique, Journal of Acoustic Emission, vol. 17, no. 3/4, pp. 97-110.

Karakus M., Perez S., 2014, Acoustic emission analysis for rock-bit interactions in impregnated diamond core drilling, International Journal of Rock Mechanics and Mining Sciences, vol. 68, pp. 36-43. https://doi.org/10.1016/j.ijrmms.2014.02.009. 
Khoshouei M., Bagherpour R., 2019, Application of Acoustic Emission (AE) in mining and earth sciences: a review, Rudarsko-geološko-naftni zbornik, vol. 34(4), pp. 19-31. https://doi.org/10.17794/rgn.2019.4.3.

Kim J., Choi Y., Choi J., Cho G., 2013, A combined method of Wigner-Ville distribution with a theoretical model for acoustic emission source location in a dispersive media, KSCE Journal of Civil Engineering, vol. 17(6), pp. 1284-1292. http://dx.doi.org/ 10.1007/s12205-013-0418-6.

Le Moal G., Rabate P., Moraru G., Véron Ph., Douilly M., 2012, A robust method for drilling monitoring using acoustic emission. [in:] Proceedings of the 9th International Conference on High Speed Machining - HSM, Mar 2012, San Sebastian, Spain, hal-01172025.

Rao S.V.S., Subramanyam B., 2008, Analysis of Acoustic Emission Signals using Wavelet Transformation Technique, Defence Science Journal, vol. 58, no. 4, pp. 559-564. https://doi.org/10.14429/DSJ.58.1677.

Raorane S., Uhl T., Packo P., 2021, Formulation and Stability Analysis of a Multi-Scale Modeling Approach for Simulation of Elastic Wave Propagation, International Journal of Computational Methods, 214101. https://doi.org/10.1142/S0219876221410103.

Sause M., Richler S., 2015, Finite element modelling of cracks as acoustic emission sources, Journal of Nondestructive Evaluation, vol. 34, 4. https://doi.org/10.1007/s10921015-0278-8.

Yu Y., Choi J., Kweon J., Kim D., 2006, A study on the failure detection of composite materials using an acoustic emission, Composite Structures, vol. 75(1-4), pp. 163-169. http://dx.doi.org/10.1016/j.compstruct.2006.04.070. 